were prepared which on distillation at $0.1 \mathrm{~mm}$. yielded $4.4 \mathrm{gm}$. of esters (sap. equiv. $263 \cdot 2$, iodine value 271.9 ; theory for methyl hexadecatrienoate, sap. equiv. 264 , iodine value $288 \cdot 5$ ).

Hydrogenation of the methyl esters in the presence of nickel formate at $230^{\circ} \mathrm{C}$. yielded methyl palmitate (m.p. $29^{\circ}$, not depressed by admixture with genuine methyl palmitate).

Bromination of the acids in ether at $-10^{\circ} \mathrm{C}$. yielded 72 per cent ether-insoluble bromides, m.p. $181^{\circ} \mathrm{C}$. (per cent $\mathrm{Br}=64 \cdot 3$, as compared with $64 \cdot 5$ per cent required for hexabromopalmitic acid).

Ester fractionation analysis showed the following composition for two samples of rape fatty acids from the lipids soluble in acetone at $0^{\circ} \mathrm{C}$. The fatty acids comprised respectively $1 \cdot 14$ and $1 \cdot 15$ per cent of the total dry matter and $24 \cdot 3$ and $23 \cdot 1$ per cent of the total lipids.

\begin{tabular}{|c|c|c|}
\hline & Saturated & Unsaturated \\
\hline $\begin{array}{l}\text { Weight } \\
\text { per cent }\end{array}$ & $\begin{array}{c}\text { (mainly palmitic) } \\
16 \cdot 0 \\
15 \cdot 1\end{array}$ & 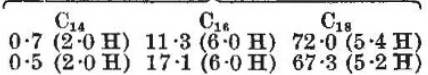 \\
\hline
\end{tabular}

The value for the mean saturation of the $C_{16}$ unsaturated acids has been calculated as $6 \cdot 0$, but this figure is only approximate, since small proportions of other less unsaturated acids may be present.

Apart from the inclusion of hexadecatrienoic acid, the fatty acid composition of rape glycerides is shown to be not dissimilar from that of forage grasses ${ }^{2}$, which from investigations to be reported elsewhere do not contain significant proportions of this constituent.

Chemistry Section,

Animal Research Division,

Department of Agriculture,

Wellington, N.Z. April 23.

${ }^{1}$ Smith and Chibnall, Biochem. J., 26, 218 (1932).

${ }^{2}$ Shorland, Nature, 153, 168 (1944).

\section{Rate of Entrance of Ammonia into Muscle Fibres in Relation to Carbon Dioxide Tension}

From previous considerations ${ }^{1}$ the following Donnan relation may be expected to apply across the muscle fibre membrane:

$$
k_{1} / k=\left[\mathrm{NH}_{4}\right]_{1} /\left[\mathrm{NH}_{4}\right]
$$

where $k_{1}$ and $k$ are the potassium concentrations within and without, and similarly for the ammonium ion.

In a communication some years ago ${ }^{2}$, it was pointed out that with an external concentration of $1 \mathrm{mgm}$. of ammonia nitrogen per $100 \mathrm{ml}$. a ratio of about $2 \cdot 1$ was reached across the membrane when the external concentration was $30 \mathrm{~m} . e q$. per litre, and the $k_{1} / k$ value could be expected to be about $4 \cdot 0$ (the high external $K$ was used to prevent $K$ losses). The result was interpreted then as a probable damage to the membrane resulting from high internal ammonia concentrations.

Later investigations have brought to light some striking facts. First, if the external ammonia be decreased below $1 \mathrm{mgm}$. ammonia nitrogen per cent under the same conditions, the ammonia ratio increases more and more until it equals that of potassium. This would be in agreement with the view that high internal ammonia concentrations were in some way affecting the balance or the permeability of ions. In addition, when we came to measure the rate of passage of the ammonium ion as described in a previous communication ${ }^{3}$, and using no carbon dioxide or bicarbonate but a little phosphate, we got no measurable rate of ammonia entrance over several hours at room temperature. We varied in turn the details of the experiments and obtained the same results. We then carried out experiments with 5 and 15 per cent carbon dioxide, maintaining the $p H$ constant by substituting the required fraction of sodium chloride by sodium bicarbonate. A great difference resulted in the rate of ammonia entrance, and with 15 per cent carbon dioxide it exceeded that of potassium chloride (without the latter being appreciably affected). This was proved by direct analyses as well as by observing the volume change.

The experiments recall the interchange of potassium and ammonia in yeast which occurs only in the presence of carbon dioxide. (The effect of carbon dioxide was many times repeated and there appears no doubt about it. A few experiments by Fenn et al. ${ }^{4}$ under different conditions would appear to indicate a different result, but these cannot be fully considered here.)

From such experiments it is clear that the undamaged muscle fibre membrane is either impermeable to the ammonium ion or is very slowly permeable, but that a great facilitation of entrance can be produced by carbon dioxide. Into ammonia equilibria or steady states across the muscle fibre membrane there enters a complexity quite absent from the simpler potassium, rubidium, chlorine, bromine, bicarbonate and hydrogen ion relationships.

The experiments of Fenn et al. ${ }^{4}$ are open to question on several important points. For example, under their conditions it can be shown that numbers of fibres are losing their differential permeability for potassium and sodium throughout, and that this loss is irreversible, a very confusing complexity being established. It may also be noted that a misleading statement occurs in their paper to the effect that since potassium diffuses out slowly from isolated immersed muscle (in ordinary Ringer fluid) the ratio of potassiumions across the membrane can be made anything one pleases by changing the external $K$, and it has therefore no significance. If, by this, it is intended to convey that $\mathrm{K}$ ratios in general across the membrane have no significance, we do not see how such can be seriously maintained in view of the evidence already considered ${ }^{1}$.

At and above the external maintenance $K$ level, a definite $\mathrm{K}$ ratio is reached and maintained for long periods (48 hours in the cold). Such ratios are in full accord with the theoretical treatment of a membrane permeable to potassium ions and small anions, but not to sodium ions and larger anions of the type of sulphate, or phosphate esters. It must be taken now as proved that the muscle fibre membrane is of such a kind, unless we are prepared to entertain very fantastic hypotheses.

E. J. Conway.

P. T. MOORE.

Department of Biochemistry, University College, Dublin.

${ }^{1}$ Boyle and Conway, J. Physiol., 100, 1 (1941).

' Conway, E. J., O'Brien, M. F., and Boyle, P. J., Nature, 148, 662 (1941).

${ }^{3}$ Conway and Moore, Nature, 156, 170 (1945). - Fenn, W. O., Haege, L. F., Sheridan, E., and Flick, J. B., J. Gen.
Physiol., 28, 53 (1944). 